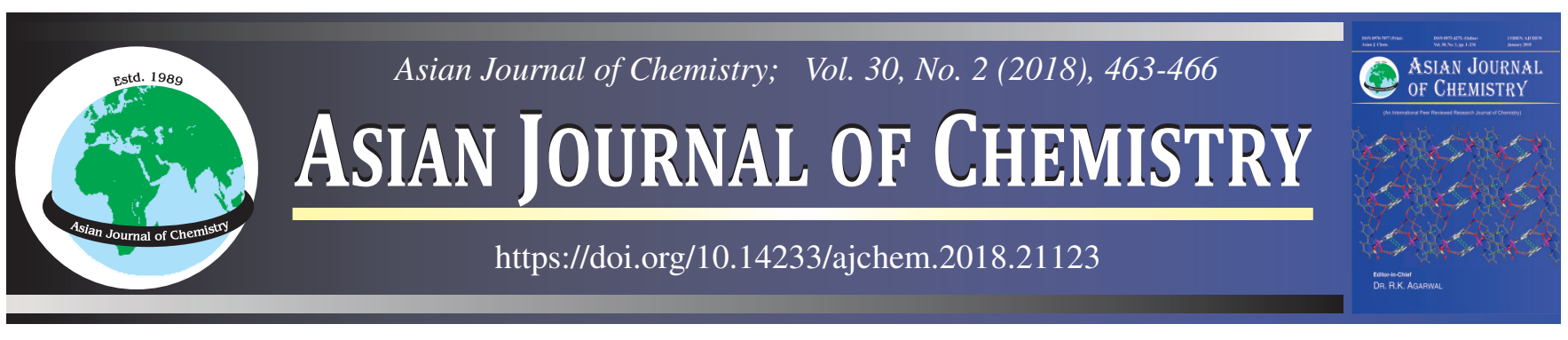

\title{
Comparison Method to Estimate Surface Directional Thermal Conductivity of Ultrathin Graphite Thermal Sheets
}

\author{
Ju Yong Cho and Won KweOn JAnG*
}

Department of Electronic Engineering, Hanseo University, Seosan-si, Chungcheongnam-do 31962, Republic of Korea

*Corresponding author: Fax: +82 41 6883448; Tel: +82 41 6601324; E-mail: jwk@ @anseo.ac.kr

Keywords: Surface directional, Thermal sheet, Ultrathin, Thermal conductivity, Steady state.

\section{INTRODUCTION}

Estimation of thermal properties of any system materials provides an important information to the design engineers whom to manage the heat generating systems. Because the heat spreading and dissipation is the key technology for most systems of semiconductor lighting and mobile communication devices [1]. Reduction of heat generation and fast heat spreading control are getting important for the application to smaller and lighter devices. Many kinds of thermal sheets have been used to protect the core devices from the spot heat up. Their shape and thickness have become compact and thinner as broadening its industrial application. The ultrathin thermal sheets of copper, aluminum and graphite have been used to minimize the device degradation and lengthen the working life time. Though ultrathin thermal sheets of graphite have provided the effective heat dissipation from microsystems such as mobile devices, there has not been enough information about their thermal property with measuring process. Most conventional measurement methods are able to cover only thicker than recent commercial thermal sheets over $100 \mu \mathrm{m}$. Many methods to investigate the thermal properties of materials in various types have been studied to develop the improved material technology $[2,3]$.

The transient plane surface method, a well-known conventional method, can measure thermal conductivity, thermal diffusivity, and specific heat capacity simultaneously at a time, but limited to the samples thicker than $3 \mathrm{~mm}$. In the dynamic method of Angstrome, the temporal behaviour of heat wave along the metal rod as a function of time can be used to measure the thermal property, but it can also be applied only to bulky sample. The other common method of laser flash method is also able to be applied thicker than $1 \mathrm{~mm}[4,5]$. Many applications to mobile communication, semiconductor lighting, heat generating core devices are pushing the rapid development of highly effective thermal materials and also reliable measuring system [6,7].

Despite many measuring methods have been introduced, to date, we could not find a proper method for measuring the thermal conductivity of the ultrathin thermal sheets. Furthermore, the surface directional thermal conductivity of ultrathin material is still being suffered from the absence of any officially certified technology. In this paper, a new approach is provided to get the practical value of thermal conductivity for graphite thermal sheets. We considered in $\mathrm{x}$ - and $\mathrm{xy}$-directional heat spreading of ultrathin thermal sheets. Three kinds of thermal sheets, copper, aluminum and graphite as functions of time and thickness at specific positions were compared to get the estimated thermal conductivity of graphite sheet.

\section{EXPERIMENTAL}

Simulation of thermal conductivity for three thermal sheets: Heat spreading measurement is a good approach to get the thermal properties of material, because thermal conduc- 
tivity is related with specific heat, thermal diffusivity can be specified as follows:

$$
\lambda=\rho \alpha C_{p}
$$

where, $\lambda$ is thermal conductivity, $\rho$ is density, $\alpha$ is thermal diffusivity and $C_{p}$ is specific heat. Fig. 1 is the experimental setup to investigate the surface propagating temporal heat flow of ultrathin thermal sheet. Thermoelectric module heat source was placed at the center of thermal sheet. The temperature profiles of thermal sheets were recorded as a function of position and compared each other.

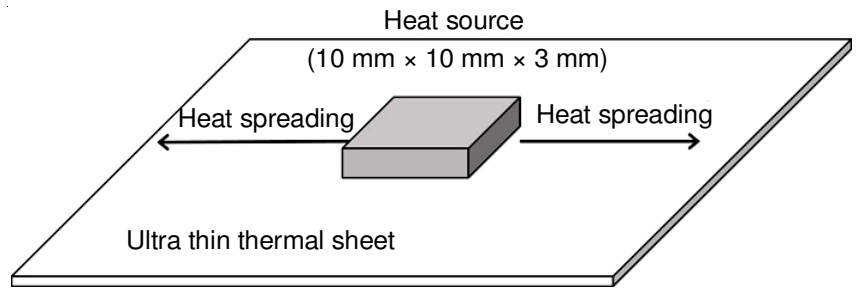

Fig. 1. Layout of heat source and ultrathin thermal sheet

\section{RESULTS AND DISCUSSION}

Three thermal sheets of aluminum, copper and graphite were investigated. Aluminum and copper are well-known materials of its intrinsic thermal properties but that of ultrathin graphite sheet is not. Some reports provided rough values of thermal properties on ultrathin graphite sheet in $\mathrm{z}$ - and $\mathrm{x}, \mathrm{y}-$ directional but it should be based on the experimental data caught by infrared camera and estimated. Comparing experimental data to well-known values of other material and estimating its certain physical property is a good approach. However, they hardly provide the detail processes how it could be evaluated.

Fig. 2 shows the temperature profiles of three thermal sheets measured at $300 \mathrm{~s}$ after the electric power turned on to the TE module. In Fig. 2, temperature around the heat source, copper and aluminum showed higher temperature profiles than that of graphite. However, at the tail of temperature profiles, $45 \mathrm{~mm}$ apart from heat source, the temperature of graphite was higher than those of other two materials. 'a' denotes the temperature difference of graphite sheet in planar direction between the center of heat source and the tail position of 45 $\mathrm{mm}$. 'b' is the temperature difference of copper, and 'c' is for that of aluminum. Fig. $2 b$ is the visual description of thermal propagation in planar direction for three thermal sheets at the same conditions of Fig. 2a. Darker part described the higher temperature and brighter part for lower temperature in twodimensional thermal profiles. Aluminum showed the largest contrast of brightness and graphite had the smallest one. In other words, the smallest difference of temperature comes from the higher thermal conductivity. After $300 \mathrm{~s}$, temperatures at every data extraction positions were stabilized as shown in Fig. 2a. Thermal conductivity of three samples can be explained with the differences between a, b and c. In Fig. 2a, the temperature difference of graphite between center and tail position, $\mathrm{a}$ is smaller than $\mathrm{b}$ and $\mathrm{c}$. It should be come from the difference of thermal conductivity of materials. Because graphite has higher thermal conductivity than copper and aluminum, the heat generated from heat source can spread to outer region better and faster than copper and aluminum. Thermal conductivities of those materials are given by the temperature profiles along the direction of the heat flow under investigation. Assuming the uniform cross-section $\mathrm{S}$ and length $\mathrm{L}$, the thermal energy conducted per unit time is:

$$
\mathrm{W}=\mathrm{k} \frac{\mathrm{S}}{\mathrm{L}} \Delta \mathrm{T}
$$

where, $\mathrm{k}$ is thermal conduction coefficient and $\Delta \mathrm{T}$ is the temperature difference between two ends of sample length $\mathrm{L}$, that is, center and tail positions of temperature profile.

At the tail of thermal profiles of three materials, we could find the big difference between graphite and other two materials. It is because graphite has higher thermal conductivity and can deliver heat rapidly and effectively. On the other hand, in case of copper and aluminum the generated heat could not be delivered to outer position rapidly. This phenomenon could also be seen in Fig. 2b. At the center of temperature profiles, the temperatures of copper, aluminum and graphite were 34.26 , 36.47 and $33.72{ }^{\circ} \mathrm{C}$, respectively. At the tail position, the temperature of copper, aluminum and graphite were 31.08, 31.08 and $31.77^{\circ} \mathrm{C}$, respectively. The temperature difference values of a, b and c were $3.18,5.39$ and $1.95^{\circ} \mathrm{C}$, respectively.

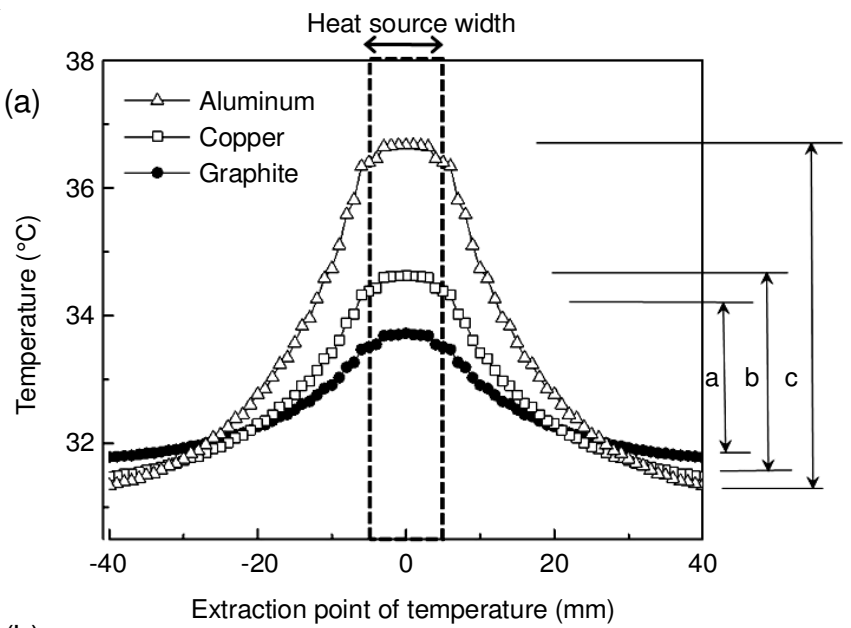

(b)

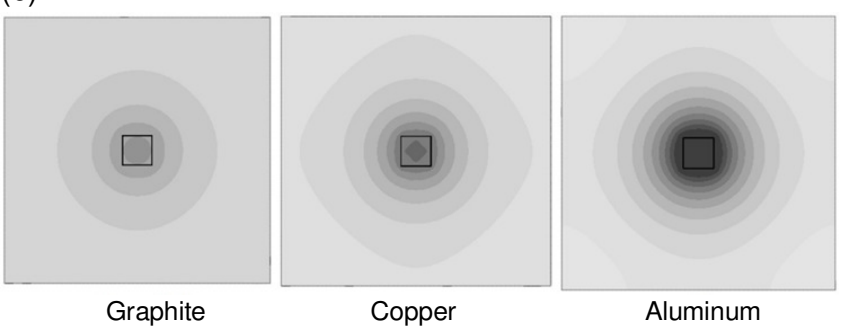

Fig. 2. Temperature profiles of three thermal sheets

The well-known thermal conductivity values of copper and aluminum are $0.401 \mathrm{~W} / \mathrm{mm}^{\circ} \mathrm{C}$ and $0.231 \mathrm{~W} / \mathrm{mm}^{\circ} \mathrm{C}$ at room temperature, when the densities of those materials are $8.94 \times$ $10^{-6}$ and $2.7 \times 10^{-6} \mathrm{~kg} / \mathrm{mm}^{3}$, respectively. The applied specific heat values of copper was $384.6 \mathrm{~J} / \mathrm{kg}^{\circ} \mathrm{C}$ and aluminum was $300.0 \mathrm{~J} / \mathrm{kg}^{\circ} \mathrm{C}$. From the relation between the thermal energy conducted per unit time, the estimated thermal conductivity of graphite were $0.654 \mathrm{~W} / \mathrm{mm}^{\circ} \mathrm{C}$ referred to copper and 0.639 $\mathrm{W} / \mathrm{mm}^{\circ} \mathrm{C}$ referred to aluminum. When the density of graphite 
is $8.5 \times 10^{-7} \mathrm{~kg} / \mathrm{mm}^{3}$, the informed value of thermal conductivity was $0.7 \mathrm{~W} / \mathrm{mm}^{\circ} \mathrm{C}$ at room temperature. The specific heat of graphite applied to the simulation was $850.0 \mathrm{~J} / \mathrm{kg}^{\circ} \mathrm{C}$. The difference between the informed value of thermal conductivity of graphite and the calculated value from the relation formula were $0.046 \mathrm{~W} / \mathrm{mm}^{\circ} \mathrm{C}$ and $0.061 \mathrm{~W} / \mathrm{mm}^{\circ} \mathrm{C}$. The discrepancy rate were found to be 6.5 and $8.7 \%$, respectively.

Fig. $2 b$ is the visualized pictures of three materials describing thermal gradient at the same conditions of Fig. 2a. Darker gradient denotes higher temperature and the square at the center is the outline of heat source.

Fig. 3 describes the temperature variation as a function of time at the center position and tail positions. At the same conditions of Fig. 2, the stabilized temperatures of three materials indicate the same values of Fig. 2. At the center and tail positions, as shown in Fig. 3, when the time elapsed about $30 \mathrm{~s}$ as shown in Fig. 4, the temperature of graphite showed the stabilized value though two other materials are still increasing. At the center position, the temperature of graphite early stabilized to the lower value than other two materials. On the other hand, at the tail position, the temperature of graphite early stabilized to the higher value than other two materials. This phenomenon can be understood as the thermal characteristics of graphite is
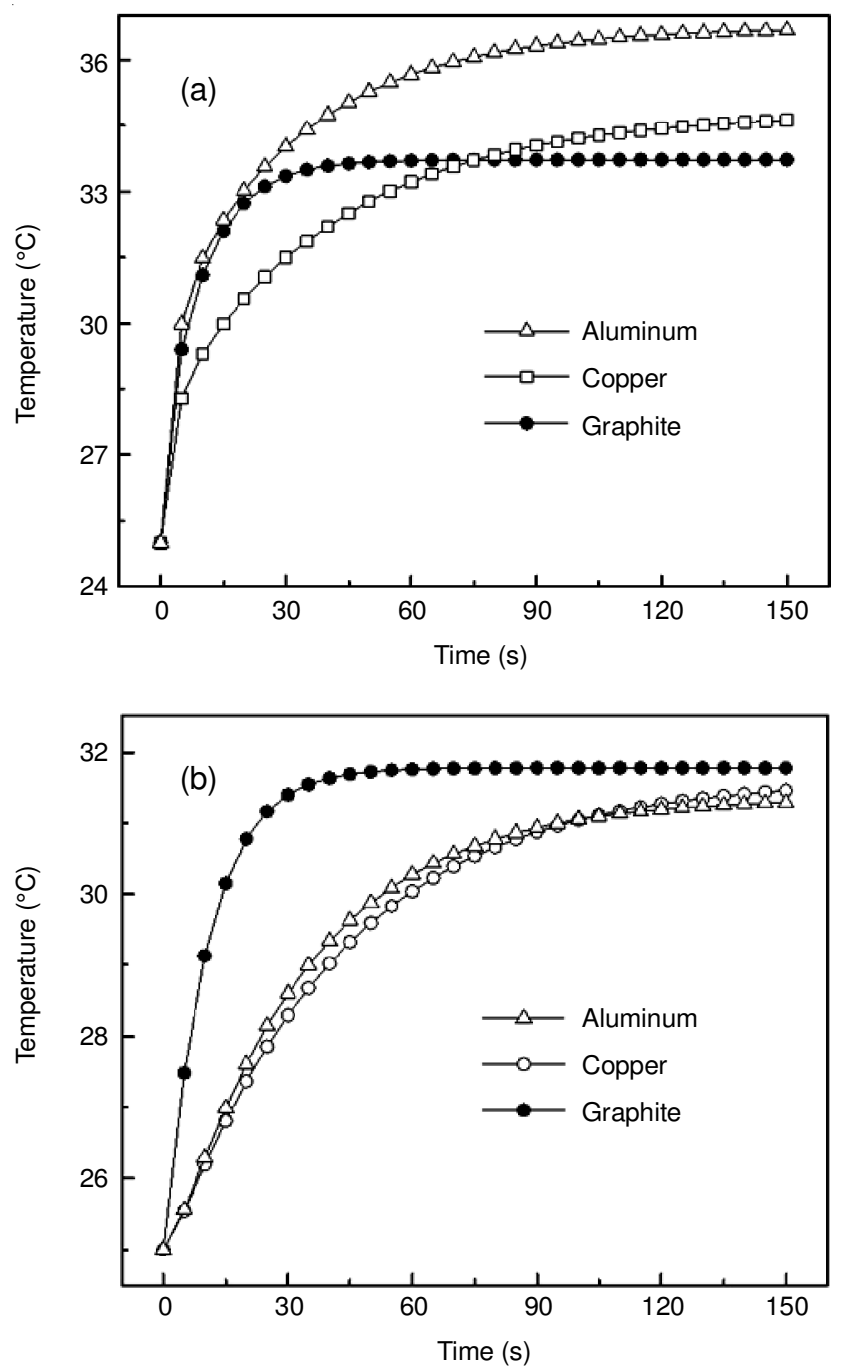

Fig. 3. Temperature variation with time (a) at the center position and (b) at the tail position

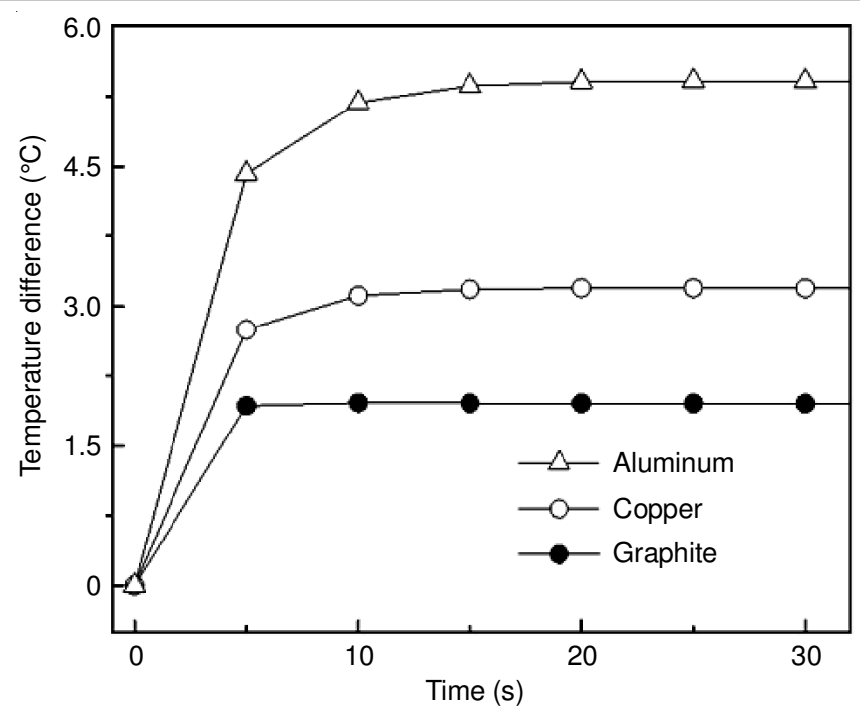

Fig. 4. Temperature difference of three materials between the center and tail positions

better than other two materials. As mentioned above, the thermal conductivity of graphite estimated higher than other two materials in proportion to the ratio of a, b, and c (Fig 2a). The simulation was performed under the same conditions of Fig. 2a.

Fig. 4 shows the temperature difference of three materials between the center and tail positions as a function of time and also provided the reason why the steady state to estimate the surface direction thermal conductivity was assumed. After about $15 \mathrm{~s}$, there was not a meaningful change of temperature difference in any material, which means that the surface thermal conductivity of ultrathin graphite sheet can be estimated only with the temperature difference values at steady state. Graphite showed the lowest temperature difference among three samples and the highest temperature difference was appeared in aluminum as expected. At steady state, the temperature differences of three materials were $5.38,3.17$ and $1.95^{\circ} \mathrm{C}$ in aluminum, copper and graphite, respectively.

The well-known values of thermal conductivities of copper and aluminum are 401 and $231 \mathrm{~W} / \mathrm{m} \cdot \mathrm{K}$, respectively. As indicated in Table-1, the ratio of thermal conductivities are nearly same values of the ratio of temperature difference. Temperature difference between copper and aluminum was 1.70, which was nearly same value of the inverse ratio of thermal conductivity between those two materials of 1.74 . The discrepancy between two values was only $2.3 \%$. The steady state comparison method which we proposed showed a good estimation. This steady state comparison method is applied to estimate the surface directional thermal conductivity of ultrathin graphite thermal sheet of 100 $\mu \mathrm{m}$ in thickness that produced by a commercial cooperation in Korea. The value of $0.646 \mathrm{~W} / \mathrm{mm}^{\circ} \mathrm{C}$ is found by calculating the average of two estimated values from ratios. The reported surface directional thermal conductivities of several commercial ultrathin graphite sheets are from 0.5 to $1.8 \mathrm{~W} / \mathrm{mm}^{\circ} \mathrm{C}$, which was dependent of mass density, specific heat, purity and manufacturing process. The derived value of thermal conductivity of ultrathin graphite thermal sheet compared to the expected value. Though the thermal conductivity is intrinsic value, the various manufacturing processes with different physical conditions generate the wide range of thermal characteristics. 
TABLE-1

RATIO OF TEMPERATURE DIFFERENCE AND THERMAL CONDUCTIVITIES OF THREE MATERIALS

\begin{tabular}{ccccc}
\hline$\frac{\Delta \mathrm{T}_{\mathrm{Al}}}{\Delta \mathrm{T}_{\mathrm{Cu}}}$ & $\left(\frac{\mathrm{k}_{\mathrm{Cu}}}{\mathrm{k}_{\mathrm{Al}}}\right)_{\text {reported }}$ & $\frac{\Delta \mathrm{T}_{\mathrm{Cu}}}{\Delta \mathrm{T}_{\mathrm{Gr}}}$ & $\frac{\Delta \mathrm{T}_{\mathrm{Al}}}{\Delta \mathrm{T}_{\mathrm{Gr}}}$ & $\left(\mathrm{k}_{\mathrm{Gr}}\right)_{\text {estimated }}$ \\
\hline 1.70 & 1.74 & 1.63 & 2.76 & $0.646 \mathrm{~W} / \mathrm{mm}^{\circ} \mathrm{C}$ \\
\hline
\end{tabular}

The calculated value with the steady state comparison method was well satisfied with the expected value of it.

\section{ACKNOWLEDGEMENTS}

This work was financially supported by 2015 research grant of Hanseo University, Seosan-si, Chungcheongnam-do, Republic of Korea.

\section{REFERENCES}

1. E. Monier-Vinard, M.-N. Nguyen, N. Laraqi, V. Bissuel and O. Daniel Steady State Temperature Solution for Early Design of Annealed Pyrolytic Graphite Heat Spreader: Full Results, 15th IEEE ITHERM Conference, p. 945 (2016); https://doi.org/10.1109/ITHERM.2016.7517647.

2. A. Boglietti, A. Cavagnino, D. Staton, M. Shanel, M. Mueller and C. Mejuto, IEEE Trans. Ind. Electron., 56, 871 (2009); https://doi.org/10.1109/TIE.2008.2011622.

3. M. Smalc, G. Shives, G. Chen, S. Guggari, J. Norley and R.A. Reynolds III, Thermal Performance of Natural Graphite Heat Spreaders, Proceedings of IPACK 2005, 17-22 July (2005).

4. C.-C. Lee, H.T. Hsu, M.C. Huang and H.H. Huang, Appl. Mech. Mater, 540, 126 (2014); https://doi.org/10.4028/www.scientific.net/AMM.540.126.

5. S.K. Kim, IEEE Trans. Compon. Packag. Manuf. Technol., 2, 1838 (2012); https://doi.org/10.1109/TCPMT.2012.2212901.

6. G. A. Beck, A.A. Carter and J.F. Morris, Measurements of the Thermal Conductivity of Pyrolitic Graphite Substrates for use in SCT Modules', ATL-INDET-98-221 (1998).

7. C.A Heusch, H.-G Moser and A. Kholodenko, Nucl. Instr. Methods Phys. Res. A, 480, 463 (2002); https://doi.org/10.1016/S0168-9002(01)01208-6. 